\title{
Influence of New Media on Travel Decision Making
}

\author{
M R Dileep, ${ }^{*}$ Sindhu S† and Abduraoof Ahmed Ismail ${ }^{\ddagger}$
}

\begin{abstract}
Tourism, one of the largest industries in the world, has recorded consistent growth since the end of Second World War. Travel is a key factor in the process of tourism, where the tourist is the main player as well as the ultimate consumer of the products and services offered to him/her. A tourist's decision to travel is by itself a complex process because there are many factors that influence the decision. The New media, which has emerged in the wake of tremendous advancements in information and communication technologies is also influencing the decision making process in modern times. Here, an attempt has been done to examine the influence of new media in the various stages of decision making process and the role played by it. A questionnaire based survey was undertaken to conduct the study and the analysis reveals various kinds of influences of new media.
\end{abstract}

Keywords: New media, Tourism, Tourist, Travel and Decision making.

\footnotetext{
" Ministry of Higher Education (MoHE), CAS Salalah, Sultanate of Oman; dileepmadhav@gmail.com † KITTS, Thiruvananthapuram, Kerala; sindhu@kittsedu.org ‡(MoHE), CAS Sur, Sultanate of Oman; ai.abduraoof@gmail.com
} 


\section{Introduction}

Travel decision making is rather an intricate affair, which, akin to the general buying behavior process, involves a number of sequential stages beginning from need identification to post purchase behavior (Horner and Swarbrooke, 2007; Schiffman and Kanuk, 2009). A consumer in any industry is surrounded by a variety of internal and external factors while taking a decision to buy a product. Tourism, being a sector consisting mainly of service based products (Cooper, et., al, 2003), decision making in it is often remarked as a high involvement exercise (Nankervis, 2001). The inherent characteristics of tourism products, like intangibility, multitudes of industries, geographical fragmentation of the industry, and seasonality, add to the complexity in choosing the most suitable alternative and becomes a difficult one for the consumers. Again, these features necessitate procuring a large quantity of information in all the stages of buying behavior. In this context, the role of latest interactive communication technologies is paramount; since technological advances are the order of the day in every area of our life, the tourist as a consumer is influenced a lot by modern communication technology to a great extent.

New media is represented by a wide range of latest communication technologies, namely, internet, web sites and portals, chat rooms, email, social networks, digital camera, CD-ROM and DVD, mobile phone, PDA, tablet, internet telephony and virtual reality environments. In such a scenario where there is a vast electronic communication environment, decision making by a tourist involves a range of events and occasions. It should be noted that that the influence of new media is not just confined to the stage of information search alone. Hence it is important to identify the occasions and contexts where new media technologies influence a traveler and the nature of their influence. This study is undertaken with the objective of identifying the nature of influence of new media tools in the whole process of travel decision making, using a survey on a random sample consisting of Omani outbound tourists. 


\section{Travel Decision Making}

Travel and tourism, one of the largest and most dynamic global industries today, has generated about 9 per cent of total GDP and has created more than 200 million jobs across the world, representing 8 per cent of global employment (WTTC, 2005). The recent reports show that the number of international tourist arrivals has crossed one billion in the year 2012, which is a milestone in the history of tourism. The tourist, the main actor in the tourism system, is the ultimate consumer in the whole industry of tourism, and he/she buys a wide range of products and services from various business sectors belonging to the industry amalgam. This action is usually considered a complex process as the decision making in order to purchase a tourism product involves variety of activities, and deals with intangible products.

Decision making is all about how consumers make their decision in order to purchase a product (Solomon 1996; Andreason, 1965; Foxall and Goldsmith, 1994). While making the decision, the consumer makes judgments about choosing the right option (Peter and Olson, 1999). There are different dimensions with regard to the process of decision making, of which one commonly discussed is the emotional involvement of consumer, which is defined as "the mental, emotional and physical activities that people engage in while selecting, purchasing, using and disposing of products and services in order to satisfy needs and desires" (Wilkie, 1994). According to Leon schiffman and Leslie Kanuk, it is "the process of making purchase decisions based on cognitive and emotional influences such as impulse, family, friends, advertisers, role models, moods, and situations that influence purchase" (Schiffman and Kanuk, 2009). From another point of view, the consumer is considered as the problem solver engaged in goal directed activities of searching for information and finally arriving at carefully considered judgmental evaluations (Hadjiphaniss \& Christou, 2006). Many models are also there that explain the decision making process. The model suggested by Howard and Sheith (1969) view consumer behavior as the product of the objective (rational) as well as subjective (emotional) elements. The same points out the role of consumer satisfaction that the consumer seeks in relation to the purchase of goods and services, in addition to the need to clearly 
understand the motivational forces which guide the decision making aspects of consumers.

There are a number of authors who have pointed out that decision making is a process, which involves a series of stages, such as need recognition, search for information on various products according to the need, formation of alternative choices, evaluation of alternatives, act of purchase and consumption and post purchase behavior (Foxall and Goldsmith, 1994; Kotler, et.al., 2003; Horner and Swarbrooke, 2007). Some authors have suggested a number of stages in this process in different ways. While Leon Schiffman and Leslie Kanuk distinguish consumer decision making into three distinct interlocking stages such as the input stage, the process stage and the output stage, Christopher Lovelock and Jochen Wirtz divide the consumer decision making into three distinct stages as pre-purchase stage, service encounter stage and post encounter stage. (Lovelock and Wirtz, 2007). Though different authors have identified stages in different ways, almost all such concepts, in one way or other, focus on the same activities. In all the processes suggested by various experts, information search is a crucial aspect which states that information is very crucial in decision making (Lawson, 1997; Andreason,1965; Schiffman and Kanuk, 2009).

The need for information is more relevant in the context of tourism and consequentially the decision making is also of increased complexity. The service characteristics are the prime reason which makes decision making very strenuous and stressing for tourists. According to Swarbrooke and Horner, 2007, decision making in tourism is a high involvement exercise and the reasons for the same include high consumer commitment, high levels of insecurity linked to intangibility, strong influence of other people in decision making, long-term decision, high level of information search and high level of emotional significance. As suggested by Yale (1995), there are many other factors that make the travel decision making more difficult. In addition to the determinants in the buying behaviour of common products, tourist destination selection includes a number of other factors (Yale, 1995; Middleton and Clark, 2001; Mathieson and Wall, 1982). In the opinion of Horner and Swarbrooke (2007), a tourist has to take into account of various aspects while taking a decision - which destination (country, 
region, resort) to choose, which mode of travel (like scheduled air, charter air, ferry, rail, coach, car, bus) to use, which type of accommodation (Eg. serviced or non-serviced) to choose for stay, duration of the holiday, at which time of the year should the holiday be taken, whether to go on a package tour or undertake independent travel, and if choosing a package tour, which operator to contact - these are some relevant factors to consider. It is commonly understood that wherever the need for information is important, the role and influence of Information and Communication Technology is of extreme significance, and correspondingly new media. As a result of the complexity of decision making and the intrinsic characteristics of the tourism products, information need in each stage for a potential tourist is remarkably high (Cooper et al, 2003; Middleton 1994; Horner \& Swarbrooke, 2007). In this regard, new media is something that has evolved as the most crucial interactive tool due to the advancements in Information and communication technologies.

Defining new media accurately is rather a difficult task. It has been interpreted in different ways in different contexts. Whatever may be the definitions, new media generally represents a wide range of communication and interaction technologies, along with few other digital tools like advanced digital cameras used in this modern information era. Tablets and advanced mobile phones, along with Apps and newer social media have created newer waves in the communication spectrum. More and more advanced technologies are emerging and complement the way people communicate and interact with others. In this era of interactive communication, getting feedback is of extreme importance. It can also be seen that the new media has tremendously transformed the nature and speed of feedback in the communication process. Indeed, it has to be pointed out that the feedback process in new media communication is speedy and in some cases instant, as in the case of interpersonal communication. The instant and speedy feedback in new media is mainly due to the feature of high interactivity. It has been reported that the advancements in new media have created a cyber world, where diverse groups of people congregate to create and share information (Manovich, 2003). 
Hence, considering the above factors, it can be concluded that a tourist usually passes through a series of stages and activities while taking a decision with regard to taking part in a tour. In all those stages he/she requires a wide range of information and the latest interactive new media has a role to play in each of them. The study is thus pursued with the assumption that the stages involved in the decision making are motivation/need identification, information search, formation of alternative choices, evaluation of alternatives, selection, consumption and post purchase behavior.

\section{Objectives and Methodology}

The study was undertaken with the main objective to examine the nature of influence and role of new media in the decision making process of a tourist. It was done with the help of a survey conducted on sample consisting of outbound tourists from Oman. Sultanate of Oman, among the GCC countries, is a major oil exporting country in the world. The recent social transformation, especially in economic terms, has resulted in outbound travel as well and the use, particularly by the younger population, of ICT and latest technologies is also somewhat matchable with international population (ITU, 2012). The study has been done using primary data, based on the theoretical framework that the travel decision making is a process that involves sequential stages and the stages involved are motivation/need identification, information search, formation of alternative choices, evaluation of alternatives, selection, consumption and post purchase behavior. Based on the above framework a Questionnaire was created for the survey; it included different types of questions, with the first section with an objective to get the profile of the respondents, including their travel tendency and nature of travel; this was followed by 15 variables in order to measure the influence of ICTs in the travel buying behavior, with a 5 point Scale, one of the commonly used techniques used to get the degree of agreement or disagreement to the variable (Burns \& Burns, 2008). The reliability and validity of the instrument has been undertaken prior to the administration of the survey. The population consisting of young outbound tourists from Oman and a sample of fifty travelers were randomly selected as respondents. 46 properly filled up data were 
used for analysis and percentage. Weighted Arithmetic Mean has been used to get the consensus of the responses collected against the variables consisting of 5 point scale. Also, One Way ANOVA has been used to the responses of those variables to examine the normality of distribution of frequencies, by making the frequency distribution into rows and columns. The same has been undertaken with the conceptual assumption that there will not be a significant difference in the rows and columns of the responses furnished on a five point scale. It was done using Microsoft Excel, with the hypothesis that there is no significant difference in the rows and columns of the frequency distribution. If the calculated value is less than the table value, then the hypothesis will be accepted, and vice versa.

\section{Results}

As mentioned before, 50 respondents were approached for the survey and among them, forty six responded. Among these, sixty three percentages were men and the remaining were women. Regarding the age group, twenty one (45\%) were in the age group between 21 and 25, and 11 (24\%) were between 26 and 30 years of age. Eight $(17 \%)$ were between 31 and 35, two were between 36 and 40 and the remaining (4) were less than 20 years. It means that majority of them belonged to the age group between age 21 and 30 yrs. Regarding occupation, $12(26 \%)$ of them were students, 16 (35\%) were government employees, $6(13 \%)$ were from the private sector, $2(4 \%)$ were unemployed, $6(13 \%)$ had own business and four belonged to other categories. All of them are educated. Majority was bachelor degree holders (20-40\%), followed by post graduates (12) and diploma holders (8) and six had education up to grade 12 . Among the respondents, thirty three $(72 \%)$ had travelled more than twice to foreign countries for visiting. Regarding the use of social network except ten (22\%), others have an account. Also, except three of them, all had carried mobile phone when they travelled outside the country during the holiday. Of those travelled, 52 percentages usually travelled with Tour Operation Company, whereas the remaining does not depend on Tour operation companies. Except eight percent, all of them had visited different websites before the last outbound tour. 


\section{Discussion}

The second section of the questionnaire consisted of 17 variables in the form of statements in order to measure the degree of agreement or disagreement of the respondent on the issues raised. A five point scale was used for the same and the response thus collected is analyzed below. Percentage and Weighted Arithmetic mean (higher mean value represents higher significance) has been used for the acceptance of the variable.

The first variable is about the influence of Internet, which is the most cost effective interactive tool, in the buying behavior of the tourists. The vast majority of the respondents (35\% strongly agree and $52 \%$ agree. Mean- 4 ) are of the view that Internet has played a role in identifying the need to engage a holiday. It denotes that among the travelling population Internet has an influence in the need recognition stage of the decision making process. It further denotes that the Internet in this stage acts as a reason for need identification for travel or as an agent of arousal for the young Omani outbound tourists. A lot of instances can be identified as to how Internet influences need identification. For instance, when one potential traveler is using a social media, he/she is persuaded to see details about the trip stories/reviews or photos. A friend can simply highlight his/her awesome experience which he/she had as part of the tour, which can arouse interest in the potential tourist. The potential tourist can also visit through some travel sites/blogs. Such visits definitely bring in some interest for a tour.

The next variable was to make out what exactly in the Internet had contributed to the need recognition to the respondents. The major New media tools such as online ads, other visual displays, travel related blogs, travelogues or travel stories on websites, and the like are the major tools that influenced the Omani outbound tourists during the stage of need recognition (48\% strongly agree and $32 \%$ agree to this. Mean 3.8). This gives the inference that all the latest new media tools are of some influence for the young outbound tourists in identifying the need for travel as they are exposed to Internet in a considerable manner. 
The following variable was on the dependence on Internet for information search, which usually forms the second stage in the decision is making process. In this also, a vast majority (35\% strongly agree, $43 \%$ agree, mean-4.1) have opined that they depended on Internet for getting information on various tourism options, like attractions, facilities, climate conditions and the similar information relevant to the tour. Such tools offer most cost effective media for information gathering. Internet is indeed very popular for information gathering as well. This variable was followed by another variable with almost the same focus, but inquiring about other new media tools. In this case also, majority agreed to this question (strongly agree $24 \%$ and agree $52 \%$. Mean 3.5 as per the response received.) This denotes the influence of new tools like tablet systems, PDAs, etc.

Selection of alternatives is another major activity involved in the decision making. This aspect is the focus of the next variableadvertisements/ other visual displays / travel related blogs / travel stories on websites have influenced much in identifying destinations and attractions. Similar to information search, the potential tourist can go for evolving alternatives as per his/her needs and interests through the websites. In fact there are different types of websites with tour planning solutions. Against this variable also, a lion's share of the respondents are of the opinion that cyber tools have played a crucial role in the identification of different destination and attractions, a stage that can be labeled as formation of alternatives. More than 80 percent of respondents agree with this, with a mean score 39 . The following variable'Internet helped me in identifying a number of varieties in terms of attractions and products' was also asked with the above objective. It could be gained that a majority of respondents (strongly agree$28 \%$, agree $41 \%$. Mean score-3.6) agreed. This further reiterates the opinion that Internet is one important source for formation of alternatives in the process of decision making.

The next variable-I was on depending more on New Media tools for getting information, than traditional media like Books, News papers, Brochures and Television reports and this was given with the aim to compare the dependence on new interactive new media tools with the traditional technology tools. With an agreement of 
seventy percent of the respondents (Mean-3.6), it denotes an important point that the young travelers depend more on new media tools than traditional tools. A variety of information sources is there on new media, ranging from official web portals of destinations to personal blogs. Here new media takes the role of the most convenient form of information source, whereas the traditional tools have been found to be relatively less convenient. As far as Oman is concerned, 'Friends and Relatives' is an important source of information and also for getting reliable advice and suggestions about various travel information, but the point to consider is that, such information as well as advice/suggestions are also reaching the potential traveller through new media tools, like e-mails, social media, and the like. The next variable- I have got information from friends through social networks, also attempts to get the opinion of respondents on the above and the same, though marginally, was agreed (strongly agree-22\% and agree-39\%, mean 33.4 ) by the respondents. The point to consider is that even in the case of information source as 'friends and relatives', it is transmitted through the new media tools. Hence, indirectly also, the latest interactive new media tools contribute to information transaction between the potential tourist and the information sources. Ninth variable was about information transaction using internet telephony services. Most of the respondents did not agree with this (only 33\% agree to it in total, mean-2), which denotes that Internet telephony services are not common among the young outbound travelers in Oman.

Soon after forming the alternatives, the potential tourist looks for the evaluation of alternatives as per his/her need or interest. The next variable was about the use of Internet to evaluate the alternatives once the potential consumer gathers information and forms the alternatives. A considerable majority of the consumers agreed (26\% strongly agree and $41 \%$ agree. Mean-3.4) with this variable. After gathering various options for tour, I used new media tools like Internet especially to compare the options, namely, visiting websites of different companies to see the prices, facilities, ratings, etc. This gives the inference that even after the information search and formation of alternatives stages, the respondents may depend on Internet for evaluation of the alternatives. The potential 
tourist uses the internet for evaluating the price, product features, benefits of each option, and the like. Next variable is an extension of the above variable, where the use of other new media tools for evaluation of alternatives was enquired. The variable is 'also, I contacted some friends and others over mobile phones, email, etc to compare the options I gathered'. The response was very positive as the majority of them agreed with it (strongly agree 15\% and agree $55 \%$, Mean 3.4). We see here the indirect influence of the new interactive new media tools where the medium of communication is new media.

The next variable that followed the above was about another dimension of the use of Internet for alternative evaluation- 'I considered ratings about hotels given as reviews by past costumers in the Internet, while booking rooms in the place where I visited.' There are many websites where customers rate the performance of the products they had used and tourism product rating sites are commonly seen in Cyber space. In Tourism, hospitality products are one of the main products rated by customers. A marginal majority (total 63\% with agreement, Mean 3.2) of the respondents have agreed with this. The above variable was followed by a statement summarizing the essence of the above two variables'Comparison of options using latest new media tools really helped me to select the right option for the tour.' For this variable, a majority of the respondents (more than $75 \%$ agree and mean 3.6) have agreed saying that such tools have really helped in comparing the alternatives identified by the potential travelers and this further cements the opinion that the latest new media does have a role to play in the decision making process even after formation of the alternatives based on the information search.

The following variables made an attempt to gather the opinion on dependence or use of latest interactive technology tools during the process of consumption of the tourism and hospitality products. The first two variables such as 'During the tour, I communicate with other members in the group and the industry like hotels, using mobile or internet tools', and 'During the tour, I communicate with family members/relatives- those who are in home using new media tools', are about communication to get latest information from the supply side as well as from personal 
sources. These two variables also got a considerably good majority of agreement (agreement $68 \%$ and $74 \%$ and mean scores 3.3 and 3.5 respectively) from the respondents. Thus new media tools are depended in the consumption stage as well. So we see that new media can be depended for communication with service providers, etc. so as to enjoy the consumption better or to make it smoother.

Table 1 New Media in tourist Decision Making

\begin{tabular}{|c|c|c|c|c|c|c|}
\hline \multicolumn{7}{|c|}{ ANOVA: Single Factor } \\
\hline Summary & & & & & & \\
\hline Groups & Count & Sum & Average & Variance & & \\
\hline Row 1 & 17 & 205 & 12.05882 & 20.18382 & & \\
\hline Row 2 & 17 & 349 & 20.52941 & 15.01471 & & \\
\hline Row 3 & 17 & 100 & 5.882353 & 6.860294 & & \\
\hline Row 4 & 17 & 119 & 7 & 10.625 & & \\
\hline Row 5 & 17 & 9 & 0.529412 & 1.264706 & & \\
\hline ANOVA & & & & & & F crit \\
\hline $\begin{array}{c}\text { Source of } \\
\text { Variation }\end{array}$ & SS & df & MS & F & P-value & \\
\hline $\begin{array}{c}\text { Between } \\
\text { Groups }\end{array}$ & 3868.424 & 4 & 967.1059 & 89.63227 & $9.36 \mathrm{E}-29$ & 2.485885 \\
\hline $\begin{array}{c}\text { Within } \\
\text { Groups }\end{array}$ & 863.1765 & 80 & 10.78971 & & & \\
\hline Total & 4731.6 & 84 & & & & \\
\hline
\end{tabular}

\section{Significance level 0.05}

The sixteenth variable in this section also deals with dependence on technology tools during consumption of the product, but from a different perspective. The variable- 'During the tour, I used new media tools as facilitator and enhancer of my enjoyment' also got agreement from a good majority of respondents (strongly agree $22 \%$ and agree $46 \%$, mean score 3.6). Interactive new media tools like web sites, chat rooms, social media, tabs and interactive platforms, and virtual reality environments do enable them to enjoy during the free hours of the tour, instead of spending idle time. These points out that such tool do enhance the tourist experience. Digital cameras, mobile cameras and similar tools help the tourist to keep the memories alive and also help them to share these experiences in the cyberspace. Feedback comes instantly on 
the new media tools. This shows that influence of new media even after consumption of the product.

As a conceptual assumption, the responses of the sample should vary and an ideal response should have a normal frequency distribution. To check the normality of frequency distribution, Single Way ANOVA Test has been done, using Microsoft Excel, with the hypothesis that there is no significant difference in the rows and columns of the frequency distribution table. The result of the test is given in table 01 . The calculated $\mathrm{f}$ values are less than the table value and hence the hypothesis is accepted, that is, there is no significant difference in rows and columns. This denotes that the responses by the sample vary and the frequency distribution is considerable.

The findings of the study are summarized as follows. Internet plays a significant role in identifying the need to engage a holiday, which points out the influence of the Internet in the need recognition stage. The study reveals that Internet in that stage acts as a reason for need identification for travel or as an agent of arousal for the young Omani outbound tourists. As the study indicates, all the latest new media tools are of some influence for the young outbound tourists in identifying the need for travel as they are exposed to Internet in a considerable manner. In the information search stage, Internet and other new media tools are used extensively by the young travelling population, as per the study. Such tools offer the most cost effective service for information gathering. The next stage as per the theoretical framework is the selection of alternatives and the study also reveals IT tools like websites influence a lot in identifying destinations and attractions. Similar to information search, in order to evolve alternatives, the sample of the study has also used IT tools effectively. The analysis also brings out an important point that the young travelers depend more on new media tools than traditional tools. Since a variety of information sources is there, new media takes the role of the most convenient form of information source. Even while getting information from friends and relatives, new media takes the indirect role of media for communication exchange. For evaluating alternatives too, new media plays a role. Internet is used especially 
to compare the options, by visiting websites of different companies to see the prices, facilities, ratings, etc. The potential tourist may use the internet for evaluating the price, product features, benefits of each option and the like. Other media are also used for the same purpose and the new media becomes a tool for interactive communication. Comparing the alternatives on the opinion websites is also prevalent among the respondents. This proves that the latest new media has a role to play in decision making process even after formation of the alternatives. While the tourist consumes the product also, new media tools play a significant role. They help to communicate with people concerned, interact with service providers and to experience the tour better. For the respondents, new media tools act as facilitator and enhancer of enjoyment ultimately. A trip has a post consumption stage in which the tourist recollects memories, share them, offer feedback and so on, and new media plays a significant role on these occasions as well.

\section{Conclusion}

Indeed, Tourism industry cannot keep its eyes shut on the potentials of New Media, especially from the point of view of marketing and promotion. The emerging trends include the increased usage of hand held devices for information search and sort of things, and the intensive use of social media in various aspects. This study was undertaken with the objective of identifying the role and relevance of new media in travel decision making and the study established the following: New media now has taken a significant role in many of our day to day activities. Taking a decision to travel by a tourist is an activity of extreme difficulty due to the inherent characteristics of tourism products and services. Decision making is usually done through a process involving different stages. The influence of new media is inevitable in need identification for travel, in information search, in identifying the alternatives for travel, in choosing the right travel option, while travelling, as well as after the travel in giving feedback and sharing the experiences. Along with helping in identifying the need for travel, new media helps to form the right option for taking a tour as well as to make the consumption easy and enjoyable. In conclusion, new media has a very significant role 
in the entire process of decision making by tourists. There have been a few limitations to the study: the study relied on a small sample. There is certainly scope for further research into the pattern of influence, use of social media, etc. in detail. The industry has to consider the new opportunities and the challenges posed by the new media especially while doing marketing and promotion.

\section{References}

Andereck, K. L., \& Caldwell, L. L. (1993). The influence of tourist characteristics on ratings of information sources for an attraction. Journal of Tourism Marketing, 2(2/3), 171-189. doi:10.1300/J073v02n02_11

Andreasen, A. R. (1965). Attitude and consumer behavior: A decision model in new research. In L. Preston (Ed.), Marketing (p.1-16). California: Berkeley, CA: Institute of Business and Economic Research.

Buhalis, D. (2003). E-Tourism: Information technology for strategic tourism management. London: Pearson.

Burns, A., \& Burns, R. (2008). Basic marketing research (Second Ed.). New Jersey: Pearson Education.

Cooper, C. P., Fletcher, Gilbert and Wanhill. (1993). Tourism: Principles and Practices. London: Pitman.

Foxall, G. R., \& Goldsmith, R. E. (1994). Consumer psychology for marketing, London: Routledge. doi:10.1111/j.1470-6431.1995.tb00535.x

Hadjiphanis, L., \& Christou, L. (2006). The role of ecommerce on consumer behaviour. Journal of Business Administration , 5(1), Retrieved from www.atu/business/spring2006/

Horner, S., \& Swarbrooke, J. (1996). Marketing tourism, hospitality, and leisure in Europe. London: International Thomson Business Press.

Horner, S. \& Swarbrooke, J. (2007). Consumer behaviour in tourism, 2nd edn., Oxford: Butterworth-Heinemann. doi:10.1002/jtr.414

International Telecommunication Union. (2012, April 12). ICT adoption and progress in the Arab region. Retrieved from http://www.itu.int/ dms_pub/itu-d/opb/ind/D-IND-AR-2012-PDF-E.pdf Kotler, P., Bowen, J., \& Makens, J. (2003). Marketing for hospitality and tourism. Oxon: Prentice-Hall, Inc. 
Kotler, P., Bowens, J. T., \& Maken, J. (2009). Marketing for tourism and hospitality. London: Prentice Hall.

Laws, E. (1997). Managing packaged tourism. London: International Thompson Business Press.

Lawson, R. (1997). Consumer decision making within goal driven framework, Psychology and Marketing, 14(5), 427-449. doi: 10.1002/(SICI)1520-6793(199708)14:5<427::AID-MAR1>3.0.CO;2-A

Lovelock, C. \& Wirtz, J. (2007). Services Marketing: People, technology, strategy. New Jersey: Pearson Prentice Hall.

Manovich, L. (2003). New media from borges to html. In N. WardripFruin \& N. Montfort (Eds.), The New Media Reader Massachusetts: Cambridge.

Middleton, V. T. C., \& Clarke, J. (2001). Marketing for Travel and Tourism. New York: Butterworth-Heinemann.

Nankervis, T., \& Kelly, I. (2001). Visitor destination, 33 Park Road Qld: John Wiley \& Sons Australia.

Peter, J. P., \& Olson, C. J. (1999). Consumer decision making, consumer behaviour and marketing strategy, Boston: Irwin/McGrawhill.

Schiffman, L. G. \& Kanuk, L. L. (2000). Consumer behavior. New Jersey: Prentice-Hall.

Schiffman, L. G. \& Kanuk, L. L. (2009). Consumer behaviour. New Jersey: Pearson Prentice Hall.

Solomon, M.R. (1996). Consumer behaviour. New Jersey: Engle-wood Cliff.

Wilkes, W.L. (1994). Consumer behaviour. New York: Wiley.

WTTC, (2005). Annual report on tourism performance, World travel and tourism council.

Yale, P. (1995). The business of tour operations. London: Longman Group Limited. 